\title{
ДИНАМИЧЕСКИЕ НАРУШЕНИЯ \\ ВЕНОЗНОГО КРОВООБРАЩЕНИЯ МОЗГА ПРИ \\ МИОФАСЦИАЛЬНОМ БОЛЕВАОМ СИНДРОМЕ (МФБС) ШЕИ
}

\author{
*ХУРДА СЕРГЕЙ ГРИГОРЬЕВИЧ \\ Неврологическое отделение № 2 Городской больницы № 2 г. Краснодар, РФ
}

В статье представлены результаты клинико-функционального исследования 117 больных. Показана роль миофасциального болевого синдрома шеи и плечевого пояса в патогенезе развития динамических нарушений венозного кровообращения головного мозга. Представлен алгоритм диагностических и лечебных мероприятий.

Ключевые слова: миофасциальный болевой синдром, головная боль.

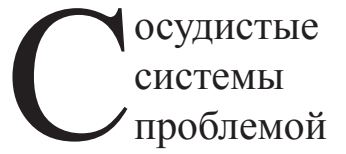

поражения нервной

являются важной

современной

клинической неврологии. В этом аспекте, нарушения венозного кровообращения головного мозга являются важной частью сосудистых заболеваний человека. В сущности, венозная гемодинамика является частью всей гемодинамики мозга, включая внечерепное кровообращение [1, 2]. В этом смысле, в клинической картине общих дисциркуляторных расстройств, мозговые венозные составляющие могут оказаться ведущими.

Миофасциальные болевые синдромы, составляющие основу болезненности позвоночника, проявляются как локальным болезненным спазмом мышц, так и вторичными местными или региональными вегетативными реакциями (сосудистые, секреторные и пиломоторные изменения) [3, $4,5,6,7]$. В этой публикации показана роль миофасциального болевого синдрома шеи и плечевого пояса в развитии динамических нарушений краниального венозного кровообращения.

Цель исследования: установление роли миофасциального болевого синдрома шеи и плечевого пояса в развитии динамических нарушений краниального венозного кровообращения.

Поставленная цель конкретизирована следующими задачами:

- Уточнение клинические вариантов особенностей расстройств венозного кровообращения головного мозга при миофасциальной боли шейной локализации.

- Оценка клинических особенностей мускулатуры шеи различной локализации при формировании нарушений венозного оттока из полости черепа.

- Разработкакритериевдиагностикиипрогноза расстройств венозного кровообращения головного мозга при МФБС шейной мускулатуры различной локализации.

- Обоснование схем дифференцированной терапиибольныхсвыявленныминарушениями краниального венозного кровообращения при МФБС шейной локализации.

Материал и методы исследования. Материал настоящего исследования получен в результате обследования 117 пациентов, страдающих цервикокраниалгией и головными болями различного происхождения. Основную группу (1 группа) составили больные с клиническими проявлениями динамических нарушений венозного краниального оттока, одновременно страдающие МФБС шеи и плечевого пояса - 65 человека; группу сравнения (2 группа) - больные с клиническими признаками головной боли венозной недостаточности (ГБВН) без МФБС шейной локализации - 32 пациента. Контрольная группа (3 группа) МФБС шеи - 20 человек. 
Критерии

формирования

исследования:

1. В основную группу исследования вошли пациенты, страдающие церебральными венозными дистоническими гемодинамическими нарушениями со средней степенью тяжести с жалобами на постоянные головные боли, усиливающиеся в горизонтальном положении и при работе с вынужденным положением головы, пастозность и отёчность лица после сна, утреннюю головную боль, повышенную утомляемость, отечность верхних конечностей. Дополнительное условие формирования основной группы клинические признаки МФБС шеи и плечевого пояса различной степени выраженности.

2. В группу сравнения - наличие клинических признаков «чистой венозной недостаточности головного мозга» без жалоб и объективных данных болевого синдрома шейной локализации.

3. В контрольную группу - пациенты с клинической картиной МФБС шейной локализации различной степени выраженности.

Критерии исключения из исследования: наличие тяжелой соматической патологии; последствия тяжелых черепно-мозговых травм, наличие органического поражения центральной или периферической нервной системы.

Проводилось

вертеброневрологическое обследование, реоэнцефалография(РЭГ)с функциональными нагрузками, по стандартной методике с целью оценки кровенаполнения вертебральнобазилярного и каротидного бассейнов, тонуса и эластичности сосудистой стенки, венозного оттока, подбора и оценки эффективности комплексной терапии, флеботонометрия, мануальная диагностика миофасциальных триггерных пунктов (МФТП) и функциональных блокад (ФБ) шейного отдела позвоночника, рентгенография шейного отдела позвоночника ультразвуковая (УЗДГ) и транскраниальная допплерография (ТКДГ) сосудов головного мозга и брахиоцефальных сосудов, По показаниям ряду больных проводились эхоэнцефалография (ЭхоЭГ), электроэнцефалография, томография головного мозга и шейного отдела позвоночника, магнитно-резонансная томография (МРТ) головного мозга.

Степень болевого ощущения и другие клинические явления, возникающие при кинестезической пальпации мышцы, определяли по схеме:

1 степень - спонтанная боль отсутствует, локальный мышечный гипертонус одной мышцы без триггерых феноменов.

2 степень - имеется спонтанная боль в одной мышце, локальный мышечный гипертонус с триггерными феноменами $[3,4,7]$.

3 степень - диффузная выраженная боль в покое и в группе мышц, усиливающаяся при любом движении, выраженные триггерные феномены.

Результаты. Средний возраст всех обследуемых пациентов составил $39,7 \pm 10,2$ лет. В основной группе давность заболевания - от 1года до 5 лет составила $54,7 \%$, от 6 до 10 - 25,5\%. Больные в группе с ГБВН имели давность заболевания от 1 до 5 лет - 68\%, от 6 до 10 лет - 14\%. Средний возраст начала

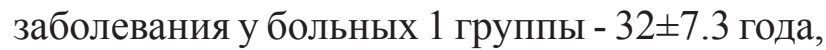
у пациентов 2-ой группы - 31+5,7 лет.

Для уточнения различий в группах обследованных нами больных МФБС шеи с ДНВК, ГБВН и группой сравнения проводился анализ общих жалоб, предъявляемые всеми пациентами.

Отечность лица, особенно в утренние часы, беспокоило пациентов с ГБВН $(90,6 \%)$ и МФБС шеи с ДНВК $(15,2 \%),(p<0,01)$. Значительно чаще пациенты с ГБВН предъявляли жалобы на: нарушение сна (75,0\%), с МФБС шеи с ДНВК 40,9\% ( $<<0,01)$. Повышенная утомляемость чаще беспокоила пациентов с МФБС шеи с ДНВК (92,4\%) по сравнению с больными ГБВН $(68,7 \%)$, $(p<0,01)$, пациенты контрольной группы жаловались на утомляемость в 90\% случаев. Жалобы на боли в шее, иррадиирущие в надплечьеимелинаибольшеераспространение в первой группе $(63,6 \%)$, меньшее в третьей 
группе $(35,0 \%)$. Во второй группе данный показатель отсутствовал. Все больные в трех сравниваемых группах жаловались на головные боли. Диффузная головная боль среди всех сравниваемых групп преобладала у больных с ГБВН и достоверно отличалась $(\mathrm{p}<0,001)$.

У больных с МФБС шеи и ДНВК в 100\% отмечалась сильная и умеренная боль в шее, и достоверно преобладала по сравнению с пациентами 2-ой и 3 -ей групп $(p=0,02)$. Пациенты с ГБВН предъявляли жалобы на умеренную 46,9\% и сильную 56,3 \% головную боль, достоверно преобладающую по сравнению с 1-ой группой $(\mathrm{p}<0,001)$ и с группой контроля $(\mathrm{p}=0,023)$.

У обследованных больных МФБС шеи с ДНВК преобладали жалобы на головные боли в дневные и вечерние часы, усиливающуюся после резких движений головы $(\mathrm{p}<0,001)$, умственного напряжения, пребывания в позе с вынужденным положением головы.

У пациентов с ГБВН преобладала умеренная и выраженная диффузная головная боль 97\%, продолжительностью от нескольких часов до суток и более, преимущественно утром, боли в затылочной и теменно-височных областях, распирающего и давящего характера. Головная боль сочеталась сутренней отечностью лица. Усиление головной боли провоцировали физическое напряжение $(\mathrm{p}=0,002)$, стресс $(\mathrm{p}<0,001)$. Пациенты с ГБВН отмечали непереносимость газированных алкогольных и сильно газированных безалкогольных напитков, провоцирующих головную боль.

У всех пациентов с ГБВН имелось расширение подкожных вен лобно-височной области $50,0 \%$ и подкожных вен шеи и верхнего плечевого пояса $50 \%$, ливедо отмечалось в $62,5 \%$ случаев и достоверно преобладало $(\mathrm{p}<0,001)$ по сравнению с больными МФБС с ДНМК, у которых наблюдалось расширение подкожных вен лобно-височной области $13,6 \%$, шеи и верхнего плечевого пояса $33,3 \%$, ливедо в 9,1\% случаев. У пациентов 3-ей группы расширенных подкожных вен и ливедо не наблюдалось.

По данным РЭГ затруднение венозного оттока было выявлено в 100\% случаев у больных с ГБВН, У больных с МФБС шее с ДНВК в 92\% , в контрольной группе 25\%. Затруднение венозного оттока 1-ой степени достоверно преобладало $(\mathrm{p}<0,045)$ у больных МФБС шеи с ДНМК в 59\%, ГБВН 37,5\%, в контрольной группе 25\%. Затруднение венозного оттока 2-й степени достоверно $(\mathrm{p}<0,006)$ преобладало у больных с ГБВН 62,5\%, МФБС шеи с ДНМК $33,3 \%$.

У больных с ГБВН, помимо нарушений венозного оттока, РЭГ характеризовалась вертеброгенным влиянием на позвоночные артерии $\quad 46,6 \%$ нормогипертоническим (50\%) и артериально-гипертоническим типом РЭГ (35,4\%), снижением пульсового кровенаполнения сосудов головного мозга (46,6\%), у больных МФБС шеи с ДНВК-артериально-гипертонический тип РЭГ (53,1\%), вертеброгенное влияние на позвоночные артерии (48\%), снижение пульсового кровенаполнения - 36\%.

По результатам кинестезической пальпации, часть мышц шеи были объединены в две группы: 1-ая подзатылочные мышцы: малая и большая задние прямые мышцы головы, верхняя и нижняя косые мышцы головы, латеральная прямая мышца головы; 2-ая передняя, средняя и задняя лестничные мышцы.

По степени болезненности мышц в 1-ой группе преобладала 2-ая и 3-я степень $(\mathrm{p}<0,001)$ по сравнению с пациентами с ГБВН. У пациентов с ГБВН диагностировались ЛМГ (латентные мышечные гипертонусы) только в подзатылочных мышцах. У больных контрольной группы преобладала 1-ая и 2-ая степень болезненности подзатылочных, лестничной и надостной мышцах.

Для уточнения связи имеющегося МФГ в мышцах шеи и нарушением венозного оттока по РЭГ до лечения у пациентов всех групп праведен анализ.

У пациентов с МФБС шеи и ДНВК выявлены следующие связи:

a) по РЭГ между венозным оттоком 1-й степени и МФГ в подзатылочных мышцах $(p=0,027)$ К Коэффициент корреляции 
Спирмена для этой связи $\mathrm{r}=0,27(\mathrm{p}=0,028)$. B случае связей между венозным оттоком 1-й степени и другими мышцами достоверных результатов не получено ( $\mathrm{p}>0,05)$.

b) между венозным оттоком 2-й степени и МФГ подзатылочными мышцами также наблюдается достоверная связь $(\mathrm{p}=0,005)$ с коэффициентом корреляции $\mathrm{r}=0,34(\mathrm{p}=0,006)$. Кроме этой зависимости выявлены две корреляционные связи. Первая - между венозным оттоком 2-й степени и МФГ в лестничных мышцах $(p=0,045) \quad$ c коэффициентом корреляции $\mathrm{r}=0,21(\mathrm{p}=0,048)$. Вторая - между венозным оттоком 2-й степени и МФГ в грудино-ключечно-сосцевидных мышцах $(\mathrm{p}=0,049)$ с коэффициентом $\mathrm{r}=0,19$ $(\mathrm{p}=0,049)$. Достоверных связей между венозным оттоком 2-й степени и другими мышцами не выявлено.

В группе больных с ГБВН и контрольной группе достоверной связи имеющихся ЛМГ и нарушений венозного оттока не выявлено $(\mathrm{p}>0,05)$.

После проведенного комплексного лечения, включающего мягкие техники мануальной терапии [4], в динамике были обследованы все пациенты. У всех больных отмечалось улучшение общего самочувствия, уменьшение или исчезновение жалоб, полное исчезновение отраженной боли, отсутствие или значительное уменьшение локальной болезненности при пальпации. Уменьшилось количество локальных мышечных гипертонусов. В процессе проводимого лечения больным повторно проводилось РЭГ, для уточнения влияния мануальной терапии на мозговой кровоток. По данным РЭГ отмечено улучшение интракраниального венозного оттока у больных на фоне лечения МФБС шеи и плечевого пояса.

В группе больных с МФБС шеи и ДНВК установлена корреляционная связь нарушений венозного оттока по РЭГ и степенью выраженности МФБС отдельных групп мышц.

Выявлена связь по РЭГ между венозным оттоком 1-й степени и МФБС 1-ой степени в подзатылочных мышцах $(\mathrm{p}=0,001)$.
Коэффициент корреляции для этой связи $\mathrm{r}=0,26(\mathrm{p}=0,032)$.

Степень выраженности МФБС шеи значительно уменьшилась, от 2-ой $(62,1 \%)$ и 3 -ей $(42,4 \%)$ до 1-ой и полного излечения, а также нормализовался венозный отток, (венозный отток 2-й степени у пролеченных пациентов не регистрировался).

В суммарном виде следует определить, что у 92\% пациентов с МФБС шеи и плечевого пояса имеются нарушения интракраниального оттока.ВгруппепациентовМФБСшеисДНМК с более высокой степенью болезненности и выявлялись нарушения венозного оттока 2 -ой $(33 \%)$ и 1-ой $(60 \%)$ степени тяжести, чаще выявляются активные миофасциальные триггерные точки с генерализованными мышечно-тоническими и вегетативными реакциями. Активность триггерных точек не только проявляется в виде отраженной боли, но и патологическим образом модулирует некоторые патологические функции центральной нервной системы. С активностью миофасциальных триггерных пунктов связаны вегетативные и проприоцептивные расстройства (нарушения равновесия, звон в ушах, головокружение). Активный МФБС шеи и плечевого пояса существенно меняет общий вегетативный тонус, усиливая проявления выраженности имеющегося синдрома вегетативной дистонии, В этой связи следует учесть, что вегетативные нервные волокна способствуют выделению альгогенов в зону отраженной боли с возникновениемноцицептивной вегетативной обратной связи, этот механизм может быть самоподдерживающимся $[5,7]$.

У больных с ГБВН не выявлялись локальные мышечные гипертонусы и регионарные мышечно-тонические реакции в мускулатуре шеи и плечевого пояса. Характеристики РЭГ у этой группы больных не зависят от исходных дегенеративных изменений шейного отдела позвоночника, нестабильностью ПДС и имеющейся незначительной вызванной болезненности подзатылочных мышц.

Дисфункция сегментарного аппарата спинного мозга является одним из основных 
этапов патогенеза МФБС. Функциональные нарушения сегментарного аппарата спинного мозга проявляются в несостоятельности механизма воротного контроля, снижении силы, нарушении реципрокных отношений и ведут к возникновению дисбаланса восходящей проприоцепции, недостаточностиантиноцицептивнойсистемы супраспинального уровня и изменению нисходящего супрасегментарного контроля. МФБС создает предпосылки для развития динамических нарушений венозного оттока, не являясь этиологическим фактором. Таким образом, ДНВК у больных с МФБС шеи является смешанным по патогенезу.

Основными звеньями патогенеза ДНВК у пациентов МФБС шеи и плечевого пояса являются:

- рефлекторное сокращение мышц шеи иразвитие болезненных локальных мышечных гипертонусов, участвующих в формировании туннельных синдромов и хронической боли из шейного отдела позвоночника.

- д дисфункция

сегментарного

аппарата спинного мозга, нарушение механизма воротного контроля и модуляции ноцицептивной афферентации на сегментарном спинальном уровне;

- $\quad$ недостаточность

АНЦС

супраспинального уровня, а также неэффективность АНЦС, обусловленная ее недостаточной ноцицептивной активацией.

Выводы:

- $\quad$ У больных с миофасциальной болью шеи и плечевого пояса нарушения венозного оттока имеют динамический характер, Это тип расстройств венозного кровообращения является ведущим (более 75\%) во всей совокупности пациентов с дисциркуляцией

\section{СПИСОК ЛИТЕРАТУРЫ}

1. Бердичевский М.Я. Венозная дисциркуляторная патология головного мозга.-М.:Медицина,1989.

2. Бердичевский М.Я., Музлаев Г.Г., Литвиненко Д.В. Современные аспекты диагностики и лечения нарушений венозного кровообращения головного мозга//Неврол.журнал-2004.-№2.-С.47-51.

3. Иваничев Г.А. Болезненные мышечные уплотнения / Г.А. Иваничев. - Казань: Изд-во венозного церебрального кровотока.

- МФБС глубоких и передних мышц шеи верхне- и среднешейных отделов оказывает патогенетически более значимое влияние на венозный отток за счет туннельно-компрессионных механизмов и встречается в 89,4\% наблюдений. При миофасциальной боли верхнешейной локализации и функциональных блокадах краниовертебрального перехода динамические венозные расстройства возникают по типу ноцицептивных моторно-вазальных рефлексов, туннельнокомпрессионный механизм в этом варианте не актуален.

- $\quad$ Разработаннаяметодикасопоставления мануальной диагностики МФБС шеи и реоэнцефалографических данных является адекватной в диагностике динамических нарушений венозного кровообращения головного мозга. Выявлено 97 больных среди обследованных 1000 человек.

- Устранение МФБС шеи и плечевого пояса оказывает быстрый благоприятный эффект на клинические и реоэнцефалографические параметры ДНВК головного мозга. Применением «мягких техник» мануальной терапии в устранении МФБС шеи и плечевого пояса достигнуто значительное улучшение в $45,0 \%$, умеренное улучшение в $36,67 \%$ и незначительное улучшение в $18,33 \%$ наблюдений. Для предотвращения хронизации комбинированного патологического процесса целесообразно сочетанное применение мануальной терапии и венотоников в структуре реабилитационных мероприятий.

КГУ, 1990. - $156 \mathrm{c}$.

4. Иваничев Г.А. Мануальная медицина: Учебное пособие / Г.А. Иваничев. - М.: МЕДпресс-информ, 2003. $-486 \mathrm{c}$.

5. Иваничев Г. А. Миофасциальная боль / Г. А. Иваничев.-Казань, 2007.-С.-392.

6. Simons D. G. Muscle pain syndromes. Fmtricfn Physical Medicine 1985; 54: 289-298. 


\title{
XÜLASə
}

\section{BOYUNUN MIOOFASSİAL AĞRI SINDROMU ZAMANI BAŞ BEYNIN VENOZ QAN DÖVRANININ DINAMIK POZULMALARI}

\author{
Xurda Sergey Qriqoryeviç \\ 2 saylı Şəhər xastaxanasının II nevrologiya şöbasi, Krasnodar, RF
}

Məqalədə 117 xəstənin kliniki-funksional müayinəsinin nəticələri təqdim olunub. Baş beynin venoz qan dövranının dinamiki pozulmalarının patogenezində boyun və çiyin qurşağının miofassial ağrı sindromunda rolu göstərilir. Məqalədə diaqnostik və terapevtik tədbirlərinin alqoritmi təqdim olunub.

Açar sözlər: miofassial ağrı sindromu, baş ağrısı.

\section{SUMMARY}

\section{DYNAMIC INFRINGEMENTS OF VENOUS BLOOD CIRCULATION OF THE BRAIN AT MYOFASCIAL PAIN SYNDROME OF THE NECK}

\author{
S.G. Khurda \\ City Hospital №2 Krasnodar, RF
}

We analyzed the result of the clinical and functional investigations of 117 (one hundred and seventeen) patients. We have shown the role of the myofascial pain syndrome of the neck and humeral belt, in the development of the infringements of venous blood circulation of the brain. The algorithm of diagnostic and medical actions is presented.

Key words: myofascial pain syndrome, headache.

Redaksiyaya daxil olub: 05.11.2011

Çapa tövsiyyə olunub: 09.01.2012

Rəyçi: Z. Sadıxova, t.ü.f.d., dosent 